\title{
A relação entre cabelos ruivos, mutação do gene MC1R, dor e anestesia: Uma revisão integrativa da literatura
}

The relationship between red hair, MC1R gene mutation, pain and anesthesia: An integrative literature review

La relación entre el pelo rojo, la mutación del gen $\mathrm{MC1R}$, el dolor y la anestesia: Una revisión integradora de la literatura

\author{
Sabrina Iracema da Silva Couto \\ ORCID: https://orcid.org/0000-0002-3864-4843 \\ Universidade Maurício de Nassau, Brasil \\ E-mail: sabrinacouto89@gmail.com \\ Luana Silva Sabino Ferreira \\ ORCID: https://orcid.org/0000-0001-5252-0882 \\ Universidade Maurício de Nassau, Brasil \\ E-mail: luana_silva000@hotmail.com \\ Maria Aparecida Guimarães da Silva \\ ORCID: https://orcid.org/0000-0001-7364-1173 \\ Universidade Maurício de Nassau, Brasil \\ E-mail: enfa.aguimaraes@gmail.com \\ Élida Lopes Barros \\ ORCID: https://orcid.org/0000-0003-1687-6317 \\ Universidade Maurício de Nassau, Brasil \\ E-mail: elidalb143@gmail.com \\ Marli Christiane Nogueira de Amorim \\ ORCID: https://orcid.org/0000-0003-4134-5980 \\ Autarquia Educacional do Belo Jardim, Brasil \\ E-mail: enf.marli@hotmail.com
}

\begin{abstract}
Resumo
Objetivo: Abordar a problemática da sensibilidade em ruivos devido a alteração no gene MC1R. Metodologia: Trata-se de uma revisão integrativa da literatura, realizada no mês de janeiro de 2021, nas bases de dados Biblioteca Virtual em Saúde (BVS), PubMed e Google Scholar, foram utilizados artigos escritos na língua portuguesa ou inglesa, publicados no período entre 2017 e 2021. Resultados: Dos 135 artigos encontrados no total, após rigor metodológico por meio dos critérios de inclusão e exclusão, foram selecionados 10 artigos, sendo 1 artigo na PUBMED, 8 no Google Scholar e 1 na BVS. A análise dos artigos encontrados foi feita de forma descritiva e predispôs a etapa de extração dos dados: base de dados, autores/ano de publicação, origem/idioma da publicação, título e temática. Conclusão: Diante dos resultados encontrados na literatura pode-se observar a deficiência de estudos brasileiros acerca do tema, mesmo sendo relevante para o âmbito da ciência, tendo em vista que é necessário conhecer o mecanismo por trás dessa mutação e através das descobertas serem desenvolvidas estratégias que possam proporcionar a essa população uma melhora na sua qualidade de vida.
\end{abstract}

Palavras-chave: Mutação; Receptor tipo 1 de melanocortina; Dor; Anestesia.

\begin{abstract}
Objective: To address the issue of sensitivity in redheads due to alteration in the MC1R gene. Methodology: This is an integrative literature review, carried out in January 2021, in the Virtual Health Library (VHL), PubMed and Google Scholar databases, using articles written in Portuguese or English, published in the period between 2017 and 2021. Results: Of the 135 articles found in total, after methodological rigor through the inclusion and exclusion criteria, 10 articles were selected, 1 article in PUBMED, 8 in Google Scholar and 1 in the VHL. The analysis of the articles found was descriptive and predisposed to the data extraction stage: database, authors/year of publication, origin/language of publication, title and theme. Conclusion: In view of the results found in the literature, one can observe the deficiency of Brazilian studies on the subject, even though it is relevant to the scope of science, considering that it is necessary to know the mechanism behind this mutation and, through the discoveries, strategies that can be developed provide this population with an improvement in their quality of life.
\end{abstract}

Keywords: Mutation; Melanocortin type 1 receptor; Pain; Anesthesia. 


\begin{abstract}
Resumen
Objetivo: Abordar el problema de la sensibilidad en pelirrojos por alteración del gen MC1R. Metodología: Se trata de una revisión integradora de la literatura, realizada en enero de 2021, en las bases de datos de la Biblioteca Virtual en Salud (BVS), PubMed y Google Scholar, utilizando artículos escritos en portugués o inglés, publicados en el período comprendido entre 2017 y 2021. Resultados: De los 135 artículos encontrados en total, luego de rigor metodológico a través de los criterios de inclusión y exclusión, se seleccionaron 10 artículos, 1 artículo en PUBMED, 8 en Google Scholar y 1 en la BVS. El análisis de los artículos encontrados fue descriptivo y predispuesto a la etapa de extracción de datos: base de datos, autores / año de publicación, origen / idioma de publicación, título y tema. Conclusión: Dados los resultados encontrados en la literatura, se puede observar la deficiencia de los estudios brasileños sobre el tema, aunque es relevante para el ámbito de la ciencia, considerando que es necesario conocer el mecanismo detrás de esta mutación y a través de los descubrimientos, estrategias que pueden desarrollarse proporcionar a esta población una mejora en su calidad de vida.
\end{abstract}

Palabras clave: Mutación; Receptor de melanocortina tipo 1; Dolor; Anestesia.

\title{
1. Introdução
}

Uma das características mais visíveis de uma pessoa é sem dúvidas o cabelo, a pele ou a cor da íris. Cerca de $90 \%$ da população mundial têm cabelos, pele e olhos pretos ou em tonalidades mais escuras. Entre as variações menos comuns está o cabelo loiro com olhos e peles claras, com apenas $2 \%$ da população. E a combinação de cor de cabelo mais rara de todas é o vermelho com pele e olhos claros, que juntamente representam apenas 1\% (Musil, 2020).

Todos os seres vivos apresentam características que foram herdadas de seus genes, variando-as, desde doenças hereditárias aos traços de fenótipos. Sendo a área da genética a ciência mais qualificada para abordar o tema, em 1955, Valverd e colegas desenvolveram um estudo, onde conseguiram correlacionar pela primeira vez o gene codificador do receptor melanocortina-1, mais conhecido como MC1R, relacionado a coloração ruiva de cabelos humanos. Este mesmo estudo evidenciou que o MC1R tem potencial para realizar mutações no organismo, como, perda de função em diversos graus, variantes do gene em in vitro conferem à pele maior sensibilidade a radiação ultravioleta (UV), colorações avermelhadas aos cabelos, endometriose, diminuição da função plaquetária e em casos mais raros deficiência no sistema imunológico (Zorina-Lichtenwalter et al., 2019; Costa, 2010; Cerqueira, 2019).

A manifestação sobre o MC1R em pessoas ruivas naturais mais perceptível foi sem dúvidas a dor, mostrando as pesquisas que, o receptor melanocortina-1 está presente nas vias responsáveis pela experiência e processamento da dor, ansiedade e medo (Frost, Kleisner \& Flerg, 2017). A dor é definida como uma experiência sensorial e emocional, de característica desagradável, sendo sua intensidade variada de acordo com o organismo de cada indivíduo, fatores externos, diversificando à aguda ou crônica. Esses fenômenos descritos foram evidenciados por vários dentistas aos longos dos anos, principalmente na América do Norte, quando eles relataram que seus pacientes apresentavam dor orofacial aguda e crônica, consequentemente pelo fator do temor a sensação dolorosa, havia diminuições de pessoas ruivas naturais em consultórios dentários (Zorina-Lichtenwlter, 2019).

A diminuição da sensibilidade aos anestésicos também foi outro fator destacado em estudos, tanto clínicos como populacionais, os quais relataram que os indivíduos naturalmente ruivos tendem a ser mais resistentes aos anestésicos locais, mais sensíveis a contatos térmicos e dor dentária, sendo essas características mais evidentes em mulheres ruivas do que em homens ruivos (Fontanillas, Kless, Bothmer, Tung \& 23andMe, 2020).

Dentro desse contexto de compreender a relação dos cabelos ruivos com a mutação do gene MC1R, bem como suas complexidades no tocante ao processo de dor e anestesia, essa pesquisa se faz necessária, principalmente porque a Literatura Brasileira é bem escassa acerca destas temáticas. Logo, o objetivo é contribuir com o tema na Literatura Brasileira, abordando a problemática da sensibilidade em ruivos devido a alteração no gene MC1R. Bem como entender o processo da mutação, compreender a questão da sensibilidade à dor e identificar as complicações na manipulação de anestésicos em ruivos. 


\section{Metodologia}

Esta pesquisa consiste em uma revisão integrativa da literatura, que é um método de investigar estudos já existentes com intuito de se obter resultados sobre um determinado tema, de forma ordenada e sintetizada. Para elaboração desta revisão integrativa, foram utilizados os procedimentos metodológicos recomendados pela literatura vigente, sendo eles: 1) Identificação do tema e da questão norteadora; 2) Estabelecimento de critérios de inclusão e exclusão; 3) Categorização dos artigos; 4) Avaliação dos resultados incluídos; 5) Interpretação dos resultados; 6) Síntese do conhecimento (Souza, Silva \& Carvalho, 2010; Botelho, de Almeida Cunha \& Macedo, 2011; Sousa, Marques-Vieira, Severino \& Antunes, 2017).

A criação deste estudo de revisão literária pautou-se na seguinte questão norteadora: Como ocorre a mutação do gene MC1R e suas associações ao processo de dor e anestesia em pessoas ruivas?

Após rigor metodológico, as bases de dados utilizadas foram a Biblioteca Virtual em Saúde (BVS), PubMed e Google Scholar. Para as bases de dados foram usados os seguintes Descritores em Ciências da Saúde (DeCS): "Mutação", "Receptor Tipo 1 de Melanocortina", "Dor" e "Anestesia". Desejando atingir todos os objetivos propostos, os DeCS foram utilizados na língua inglesa e portuguesa, de forma isolada e de forma combinada.

O levantamento foi realizado no mês de janeiro de 2021, atendendo a alguns critérios de inclusão e de exclusão. Foram excluídos trabalhos incompletos, estudos em animais, artigos que não cumpriam o período estipulado, ensaios teóricos, relatos de experiência e trabalhos que não compreendiam a temática estudada. Foram incluídos na pesquisa apenas trabalhos completos, originais, teses, dissertações ou revisões da literatura, que atendam ao objetivo desta pesquisa, escritos na língua portuguesa ou inglesa, publicados no período entre 2017 e 2021. A forma de seleção descrita na metodologia pode ser observada na Figura 1.

Figura 1 - Esquema da seleção dos artigos.
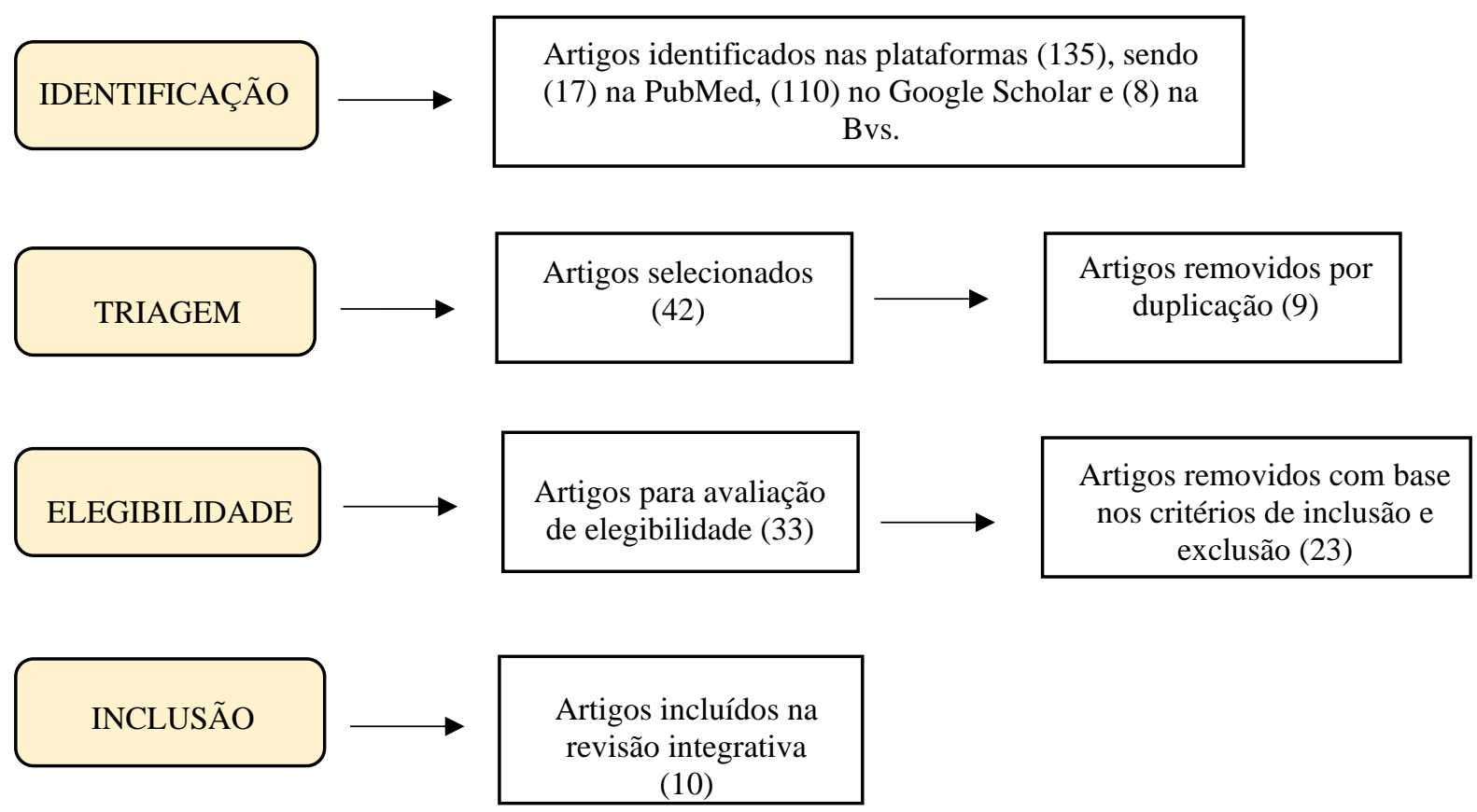

Fonte: Autores (2021). 


\section{Resultados}

Foram encontrados 135 artigos no total, após rigor metodológico por meio dos critérios de inclusão e exclusão, foram selecionados 10 artigos, sendo 1 artigo na PUBMED, 8 no Google Scholar e 1 na BVS. A análise dos artigos encontrados foi feita de forma descritiva e predispôs a etapa de extração dos dados: base de dados, autores/ano de publicação, origem/idioma da publicação, título e temática (Quadro 1).

Quadro 1 - Classificação dos artigos quanto base de dados, autor/ano de publicação, origem/idioma da publicação, título e temática.

\begin{tabular}{|c|c|c|c|c|}
\hline $\begin{array}{c}\text { Base de } \\
\text { dados }\end{array}$ & $\begin{array}{l}\text { Autor/ano de } \\
\text { publicação }\end{array}$ & $\begin{array}{l}\text { Origem/idioma } \\
\text { da publicação }\end{array}$ & Título & Temática \\
\hline $\begin{array}{l}\text { Google } \\
\text { Scholar }\end{array}$ & Musil / 2020 & Estrangeira / theco & $\begin{array}{l}\text { Asociace mezi zrzavou barvou } \\
\text { vlasů a jinými morfologickými, } \\
\text { fyziologickými a behaviorálními } \\
\text { znaky }\end{array}$ & $\begin{array}{l}\text { MC1R: estrutura, } \\
\text { função e mutação / } \\
\text { Ruivos e a dor / } \\
\text { Ruivos e a anestesia }\end{array}$ \\
\hline PUBMED & $\begin{array}{l}\text { Zorina- } \\
\text { Lichtenwalter et al. / } \\
2019\end{array}$ & $\begin{array}{l}\text { Estrangeira } \\
\text { inglês }\end{array}$ & $\begin{array}{l}\text { A study in scarlet: MC1R as the } \\
\text { main predictor of red hair and } \\
\text { exemplar of the flip-flop effect. }\end{array}$ & $\begin{array}{l}\text { MC1R: estrutura, } \\
\text { função e mutação }\end{array}$ \\
\hline BVS & $\begin{array}{l}\text { Frost, Kleisner \& } \\
\text { Flegr / } 2017\end{array}$ & $\begin{array}{l}\text { Estrangeira } \\
\text { inglês }\end{array}$ & $\begin{array}{l}\text { Health status by gender, hair color, } \\
\text { and eye color: Red-haired women } \\
\text { are the most divergent }\end{array}$ & Ruivos e a dor \\
\hline $\begin{array}{l}\text { Google } \\
\text { Scholar }\end{array}$ & $\begin{array}{l}\text { Zorina- } \\
\text { Lichtenwalter } \\
2019\end{array}$ & $\begin{array}{l}\text { Estrangeira } \\
\text { inglês }\end{array}$ & $\begin{array}{l}\text { Informed combinations: common } \\
\text { genetic variants in MC1R and } \\
\mathrm{P} 2 \mathrm{RX} 7 \text { and their effects on pain } \\
\text { phenotypes }\end{array}$ & $\begin{array}{l}\text { MC1R: estrutura, } \\
\text { função e mutação / } \\
\text { Ruivos e a dor }\end{array}$ \\
\hline $\begin{array}{l}\text { Google } \\
\text { Scholar }\end{array}$ & $\begin{array}{l}\text { Fontanillas, Kless, } \\
\text { Bothmer, Tung \& } \\
\text { 23andMe / } 2020\end{array}$ & $\begin{array}{l}\text { Estrangeira } \\
\text { inglês }\end{array}$ & $\begin{array}{l}\text { Genome-wide association study of } \\
\text { pain sensitivity assessed by } \\
\text { questionnaire and the cold pressor } \\
\text { test }\end{array}$ & Ruivos e a dor \\
\hline $\begin{array}{l}\text { Google } \\
\text { Scholar }\end{array}$ & Marcorin / 2017 & $\begin{array}{l}\text { Brasileira } \\
\text { português }\end{array}$ & \begin{tabular}{lccc} 
Avaliação & da & \multicolumn{2}{c}{ variabilidade } \\
genética do gene & MITF e suas \\
associações & com & fenótipos & de \\
pigmentação em & amostra & da \\
população brasileira & &
\end{tabular} & $\begin{array}{l}\text { MC1R: estrutura, } \\
\text { função e mutação }\end{array}$ \\
\hline $\begin{array}{l}\text { Google } \\
\text { Scholar }\end{array}$ & Long / 2018 & $\begin{array}{l}\text { Estrangeira } \\
\text { inglês }\end{array}$ & $\begin{array}{lr}\text { Pain Experiences and } & \text { Pain } \\
\text { Management Decisions: } & \text { A } \\
\text { Correlational Study } & \end{array}$ & $\begin{array}{l}\text { MC1R: estrutura, } \\
\text { função e mutação }\end{array}$ \\
\hline $\begin{array}{l}\text { Google } \\
\text { Scholar }\end{array}$ & $\begin{array}{l}\text { Zorina- } \\
\text { Lichtenwalter, } \\
\text { Maixner \& } \\
\text { Diatchenko / } 2020\end{array}$ & $\begin{array}{l}\text { Estrangeira } \\
\text { inglês }\end{array}$ & $\begin{array}{l}\text { Detangling red hair from pain: } \\
\text { phenotype-specific contributions } \\
\text { from different genetic variants in } \\
\text { melanocortin-1 receptor }\end{array}$ & Ruivos e a dor \\
\hline $\begin{array}{l}\text { Google } \\
\text { Scholar }\end{array}$ & $\begin{array}{l}\text { Packiasabapathy, } \\
\text { Horn \& Sadhasivam } \\
\text { / } 2018\end{array}$ & $\begin{array}{l}\text { Estrangeira } \\
\text { inglês }\end{array}$ & $\begin{array}{l}\text { Genetics of perioperative pain } \\
\text { management }\end{array}$ & $\begin{array}{l}\text { Ruivos e a dor / } \\
\text { Ruivos e a anestesia }\end{array}$ \\
\hline $\begin{array}{l}\text { Google } \\
\text { Scholar }\end{array}$ & Randall / 2017 & $\begin{array}{l}\text { Estrangeira } \\
\text { inglês }\end{array}$ & $\begin{array}{l}\text { Fear of Pain and Dental Care- } \\
\text { Related Fear: Associations with } \\
\text { the MC1R Gene }\end{array}$ & $\begin{array}{l}\text { Ruivos e a dor / } \\
\text { Ruivos e a anestesia }\end{array}$ \\
\hline
\end{tabular}

Fonte: Autores (2021). 
Analisando os dados do quadro, observa-se que 9 artigos foram elaborados e publicados por estrangeiros (90\%) e apenas 1 teve elaboração e publicação brasileira (10\%). Quanto ao idioma, nota-se que prevaleceram as publicações em inglês em um total de $8(80 \%)$, apenas 1 em português (10\%) e 1 também em tcheco (10\%).

\section{Discussão}

\subsection{MC1R: estrutura, função e mutação}

O receptor de melanocortina-1 ou MC1R está vinculado com à proteína G 7-transmembrana em melanócitos, os quais são encontrados nas células da epiderme, folículo piloso e os olhos. Estas células surgem durante a embriogênese, com os melanoblastos migrando da crista neural para o seu destino de ação, onde se diferenciam em dendritos especializados produtores de pigmentos (melanina) e contribuem para a aparência de cada indivíduo (Zorina- Lichtenwalter, 2019).

A produção de pigmento ou melanina ocorre dentro dos melanócitos, em vesículas chamadas melanossomos, sendo mediada por algumas enzimas que convertem a tirosina em melanina. A síntese de melanina resulta em dois pigmentos: feomelanina (pigmento vermelho-amarelo) e eumelanina (pigmento marrom-preto) (Marcorin, 2017; Leng, 2018).

No corpo humano, a pigmentação é regulada pelo hormônio adrenocortitrópico (ACTH) e $\alpha$-melanócito proteína estimuladora ( $\alpha$-MSH). Essa proteína leva a um aumento na quantidade de eumelanina, sendo seu antagonista a proteína de sinalização agouti (ASIP), que estimula a produção de feomelanina. Seguindo esse pressuposto, identificou-se que a cor ruiva é induzida por vários genes, dentre eles, OCA2, HERC2, ASIP, IRF4 e MC1R, onde este último é o mais importante de todos. Sendo que, nas pessoas ruivas, o gene deste receptor, MC1R, sofre mutações recessivas e perde parte ou toda a sua função, e como resultado há o aumento significativo da quantidade de feomelanina, a qual é responsável pelo desenvolvimento da pele clara e coloração avermelhada do cabelo (Musil, 2020; Neves, Schwengber, Albrecht, Isola \& Van der Linden, 2010).

O gene MC1R apresenta polimorfia ou seja, muda constantemente de forma, atualmente foram encontrados 80 (oitenta) tipos de alelos, a depender do país de origem das pessoas ruivas. As variantes foram apelidadas de Alelos RHC ou R, para exemplificar suas altas penetrâncias e associações com cabelos ruivos e, cada uma delas irá determinar a intensidade da coloração (Zorina- Lichtenwalter et al., 2019; Marano, Simões, Donadi \& Mendes-Junior, 2013; Almeida, 2012).

A associação com a coloração ruiva está intimamente ligada ao fenótipo recessivo sendo este, dois alelos variantes MC1R, um homozigoto (dois menos alelos das mesmas variantes) ou heterozigotos compostos (um alelo menor de duas variantes diferentes). Nos últimos 25 anos foi proposto um consenso, em que alelos MC1R, é expresso por "R", alta penetrância e, alelos "r", baixa penetrância. Alelo "R" são mais prevalentes na Europa Central e do Norte e, "r" muito presente em japoneses, chineses e tibetanos (Zorina- Lichtenwalter, 2019).

\subsection{Ruivos e a dor}

A dor é uma sensação defensiva que notifica o corpo de que está ocorrendo dano a algum tecido. Todas as pessoas têm limiares diferentes de dor, a qual não pode ser medida objetivamente, por isso é medida com base em sentimentos subjetivos de cada pessoa. De acordo com algumas pesquisas, pessoas com cabelos ruivos têm sensibilidade à dor diferente de pessoas com cabelos escuros (Musil, 2020).

Há muito se sabe que os ruivos apresentam maior risco de queimaduras solares e câncer de pele, fato esse devido o cabelo vermelho estar associado à pele clara, que é mais vulnerável à radiação UV. Só que é menos conhecido que o cabelo ruivo também está associado ao aumento da sensibilidade à dor, endometriose, doença de Parkinson, diminuição da função plaquetária e defeitos no sistema imunológico. Sendo que a associação do MC1R com os cabelos ruivos é conhecida há décadas, mas sua ligação com a dor só foi descoberta nos anos 2000 (Frost et al., 2017; Zorina-Lichtenwalter, Maixner \& Diatchenko, 2020). 
A dor é percebida através do fenômeno denominado nocicepção, pelo qual ocorre a codificação e o processamento dos estímulos ambientais físicos, químicos ou patológicos que envolvem sistema nervoso periférico e central. A nocicepção envolve uma série de componentes, incluindo os nociceptores, processos inflamatórios e vias neuronais. Eles servem para traduzir, conduzir e modular estímulos nocivos. A dor é uma experiência subjetiva e emocional, resultante da processamento complexo do estímulo nocivo na matriz da dor do cérebro. Na nocicepção, embora que o MC1R esteja satisfatoriamente presente na algia, é possível que este não participe diretamente dela e sim por mutação nos seus níveis de tradução e expressão, podendo suscitar uma resposta de loop de feedback, que pode tanto afetar a nocicepção quanto a sua inibição (Zorina-Lichtenwalter, 2019; Packiasabapathy, Horn \& Sadhasivam, 2018).

Dentre as pesquisas realizadas na área, evidenciou-se a descoberta de polimorfismos associados à variação na sensibilidade à dor, onde foram encontrados em genes de codificação para o receptor de melanocortina 1 (MC1R), o que implica na associação dos cabelos ruivos e o processo de dor (Packiasabapathy, Horn \& Sadhasivam, 2018). E em um estudo realizado por Fontanillas, envolvendo genoma e dor, foi comprovado que as mulheres com cabelos ruivos eram mais sensíveis à dor e descobriram que a variação genética no gene MC1R estava associada com um aumento na sensibilidade à dor. Onde este estudo mostrou que essa sensibilidade aumentada a dor não é tão prevalente nos homens ruivos, o que intensifica a associação com o sexo feminino. Os mesmos autores enfatizam que vários estudos clínicos e populacionais também relataram que os indivíduos naturalmente ruivos tendem a ser mais resistentes aos anestésicos locais, mais sensíveis à estímulos térmicas e dor dentária (Fontanillas et al., 2020).

Relacionado à percepção da dor, variantes do gene MC1R estão associados à redução da eficácia e ao aumento da necessidade de medicamentos gerais e locais, incluindo anestesia, principalmente em procedimentos odontológicos. A expressão de MC1R foram identificadas na região cinza periaquedutal (PAG) em células do centro de controle primário para a modulação descendente da dor. Onde foi sugerido que o envolvimento é central e/ou periférico do MC1R, para assim impactar a sensibilidade à dor, o que pode explicar em parte a relação da variação MC1R estar correlacionada com hipersensibilidade à dor (Randall, 2017; Palmeira, Ashmawi, Oliveira Junior \& Posso, 2011).

\subsection{Ruivos e a anestesia}

A anestesiologia é uma área da medicina que lida com o entorpecimento de uma parte específica do corpo (anestesia local) ou o sono profundo durante a cirurgia (anestesia geral). O processo anestésico é complexo e aponta-se que o anestesiologista deve se atentar para vários fatores, como: idade, peso, tipo de operação, genética e sexo. E existem alguns estudos que sugerem que o anestesiologista deve considerar a cor do cabelo como fator, uma vez que pessoas com cabelo vermelho natural precisam de mais anestésicos que o necessário e são mais rápidos para acordar após a anestesia do que pessoas com uma cor de cabelo diferente (Musil, 2020).

Os ruivos naturais têm uma alteração genética, que é responsável pela perda parcial ou completa da função do receptor MC1R. De acordo com alguns estudos, o rutilismo também afeta a forma como essas pessoas sentem dor e se precisam de mais anestésicos para induzir a anestesia geral. Várias pesquisas foram realizadas em animais para comprovar esses fatos e mais recentemente foram realizados estudos semelhantes em humanos. Destaca-se um estudo que foi realizado em vinte mulheres, com idade entre 21-27 anos. Dessas vinte mulheres, dez eram ruivas e dez eram de cabelos escuros, e a cor de seus cabelos era verificado com um espectrofotômetro, o qual foi usado para determinar a proporção de eumelanina para feomelanina e determinar a cor exata do cabelo. Este estudo verificou que foram necessários $19 \%$ a mais de anestésicos em mulheres ruivas para induzir o sono profundo, do que em mulheres com cabelos escuros (Musil, 2020; Lapa, 2010).

Outro estudo na área, apresentou que as variantes não funcionais do gene MC1R encontram-se associadas a diferença na analgesia, onde, as mulheres necessitam de maiores doses do que em relação aos homens. E em alguns analgésicos específicos 
como a pentazocina, um analgésico opióide, as ruivas precisam de doses menores do que o sexo oposto. Neste estudo, a variabilidade genética também foi associada ao risco da toxicidade dos anestésicos locais, onde variantes do MC1R com eficácia diminuída de lidocaína também foram descritos (Packiasabapathy et al., 2018).

Assumindo que a resistência à anestesia local pode resultar em mais dor em experiências dentárias, as quais podem condicionar o medo do tratamento dentário, pesquisadores testaram se ter variantes do gene MC1R estava associado ao medo e consequente recusa em procurar atendimento odontológico, por parte dos ruivos. Os dados da pesquisa comprovaram as duas previsões feitas previamente: 1) as variantes do gene MC1R produzem aumento da sensibilidade à dor, o que pode resultar em medo mais facilmente condicionado da dor e medo relacionado ao cuidado; 2) a redução da eficácia da anestesia associada às variantes do gene MC1R resultam em procedimentos odontológicos mais dolorosos, o que pode levar ao condicionamento do medo da dor e medo relacionado ao atendimento odontológico (Randall, 2017).

\section{Conclusão}

Contudo pode-se observar a deficiência de estudos brasileiros acerca do tema, mesmo sendo relevante para o âmbito da ciência, pois mesmo que a população que apresente a característica ruiva de pele e olhos claros seja de aproximadamente $1 \%$, a mutação no gene MC1R afeta diretamente na qualidade de vida dessa população. A maior sensibilidade a dor, a propensão ao desenvolvimento de doenças e a resistência a anestesia são pontos que devem ser estudados mais a fundo, pois diante do exposto devem ser de interesse da comunidade cientifica e de saúde em geral, pois é necessário um olhar diferenciado para a assistência à saúde dessa população.

Essa mutação do gene MC1R aponta problemáticas além do que já é muito conhecido como a necessidade de uma maior proteção solar para essa população devido a sua maior probabilidade de desenvolver câncer de pele. Os estudos ainda apontaram que as mulheres ruivas sofrem mais com as consequências da mutação gênica do que os homens, problemas como endometriose interferem diretamente na vida reprodutora dessas mulheres, pois as consequências da infertilidade podem causar diversos transtornos psicológicos e danos nos relacionamentos das mesmas.

Se faz necessário conhecer o mecanismo por trás dessa mutação e através das descobertas serem desenvolvidas estratégias que possam proporcionar a essa população uma melhora na sua qualidade de vida, uma atenção especial frente a necessidade de receber anestesias em relação a quantidade de anestésico e tempo de duração no organismo evitando que esses indivíduos possam passar por situações traumáticas durante procedimentos.

Dentro da saúde é necessário constante evolução no conhecimento permitindo assim fornecer cuidados especiais aos que necessitam, cabe dentro do princípio da equidade oferecer mais a quem precisa de mais. Desta forma, se faz necessário que estudos futuros sejam desenvolvidos nesta temática, visto que é um assunto importante para a saúde, que impacta diretamente no bem-estar dessa população de ruivos e se encontra em escassez na literatura brasileira atualmente.

\section{Referências}

Almeida, E. M. R. F. (2012). Estudo da associação de polimorfismos no gene MC1R com cor de pele e cor de cabelo para fins forenses. (Completion of course work, Repositório Institucional UNESP). https://repositorio.unesp.br/handle/11449/117988

Botelho, L. L. R., de Almeida Cunha, C. C., \& Macedo, M. (2011). O método da revisão integrativa nos estudos organizacionais. Gestão e sociedade, 5(11), $121-136$.

Cerqueira, C. C. S. D. (2009). Relação genótipo-> fenótipo e a pigmentação humana: aspectos evolutivos e sua aplicação na genética forense. (Doctoral dissertation, Universidade Federal do Rio Grande do Sul). https://www.lume.ufrgs.br/handle/10183/196604

Costa, K. A. (2010). Estudo de associação do polimorfismo de base única no códon 72 do gene humano p53 e as características de pigmentação (Doctoral dissertation, Universidade Federal de Goiás). https://files.cercomp.ufg.br/weby/up/101/o/diss_karita.pdf

Fontanillas, P., Kless, A., Bothmer, J., Tung, J. Y., \& 23andMe Research Team. (2020). Estudo de associação genoma de sensibilidade à dor avaliado por questionário e teste de prensa fria. BioRxiv,837526. 
Research, Society and Development, v. 10, n. 8, e33710817398, 2021

(CC BY 4.0) | ISSN 2525-3409 | DOI: http://dx.doi.org/10.33448/rsd-v10i8.17398

Frost, P., Kleisner, K., \& Flegr, J. (2017). Estado de saúde por sexo, cor do cabelo e cor dos olhos: as mulheres ruivas são as mais divergentes. PLoS One, 12(12), e0190238.

Lapa, T. A. S. C. (2010). Estudo farmacogenético da acção do propofol no sistema energético mitocondrial em células hela (Doctoral dissertation). http://hdl.handle.net/10316/14809

Long, P. A. (2018). Pain Experiences and Pain Management Decisions: A Correlational Study (Doctoral dissertation, University of South Dakota). https://www.proquest.com/openview/a0fc3f62c0fbd3fcc27c61b1cc4786e1/1?pq-origsite=gscholar\&cbl=18750

Marano, L. A., Simões, A. L., Donadi, E. A., \& Mendes-Junior, C. T. (2013). Análise de polimorfismos do gene MC1R associados a fenótipos humanos de pigmentação na população brasileira. Saúde, Ética \& Justiça, 18, 55-61.

Marcorin, L. (2017). Avaliação da variabilidade genética do gene MITF e suas associações com fenótipos de pigmentação em amostra da população brasileira (Doctoral dissertation, Universidade de São Paulo). https://www.teses.usp.br/teses/disponiveis/59/59138/tde-26052017143601/publico/MarcorinL.pdf

Musil, M. (2020). Asociace mezi zrzavou barvou vlasů a jinými morfologickými, fyziologickými a behaviorálními znaky. Univerzita Karlov. http://hdl.handle.net/20.500.11956/122271

Neves, A. P., Schwengber, E. B., Albrecht, F. F., Isola, J. V., \& van der Linden, L. D. S. (2017). Beyond fifty shades: the genetics of horse colors. Trends and Advances in Veterinary Genetics, 75.

Packiasabapathy, S., Horn, N., \& Sadhasivam, S. (2018). Genetics of perioperative pain management. Current opinion in anaesthesiology, $31(6), 749$.

Palmeira, C. C. D. A., Ashmawi, H. A., Oliveira Junior, J. O. D., \& Posso, I. D. P. (2011). Opioides, sexo e gênero. Revista Dor, 12(2), $182-187$.

Randall, C. L. (2017). Fear of Pain and Dental Care-Related Fear: Associations with the MC1R Gene.

Sousa, L. M. M., Marques-Vieira, C. M. A., Severino, S. S. P., \& Antunes, A. V. (2017). A metodologia de revisão integrativa da literatura em enfermagem. №21 Série 2-Novembro 2017, 17.

Souza, M. T. D., Silva, M. D. D., \& Carvalho, R. D. (2010). Revisão integrativa: o que é e como fazer. Einstein (São Paulo), 8(1), 102-106.

Zorina-Lichtenwalter, K. (2019). Informed combinations: common genetic variants in MC1R and P2RX7 and their effects on pain phenotypes (Doctoral dissertation, McGill University). https://www.proquest.com/openview/314ee67c4ad80c1cbd9c21082cd150b7/1?pq-origsite=gscholar\&cbl=18750\&diss=y

Zorina-Lichtenwalter, K., Lichtenwalter, R. N., Zaykin, D. V., Parisien, M., Gravel, S., Bortsov, A., \& Diatchenko, L. (2019). A study in scarlet: MC1R as the main predictor of red hair and exemplar of the flip-flop effect. Human molecular genetics, 28(12), 2093-2106.

Zorina-Lichtenwalter, K., Maixner, W., \& Diatchenko, L. (2020). Detangling red hair from pain: phenotype-specific contributions from different genetic variants in melanocortin-1 receptor. Pain, 161(5), 938-948. 